\title{
INTRAVENOUS METHYLENE BLUE FOR EXPERIMENTAL STUDIES ON THE CENTRAL NERVOUS SYSTEM*
}

\author{
BY \\ W. H. FEINDEL, A. C. ALLISON, and G. WEDDELL \\ From the Department of Anatomy, University of Oxford
}

(RECEIVED AUGUST 9, 1948)

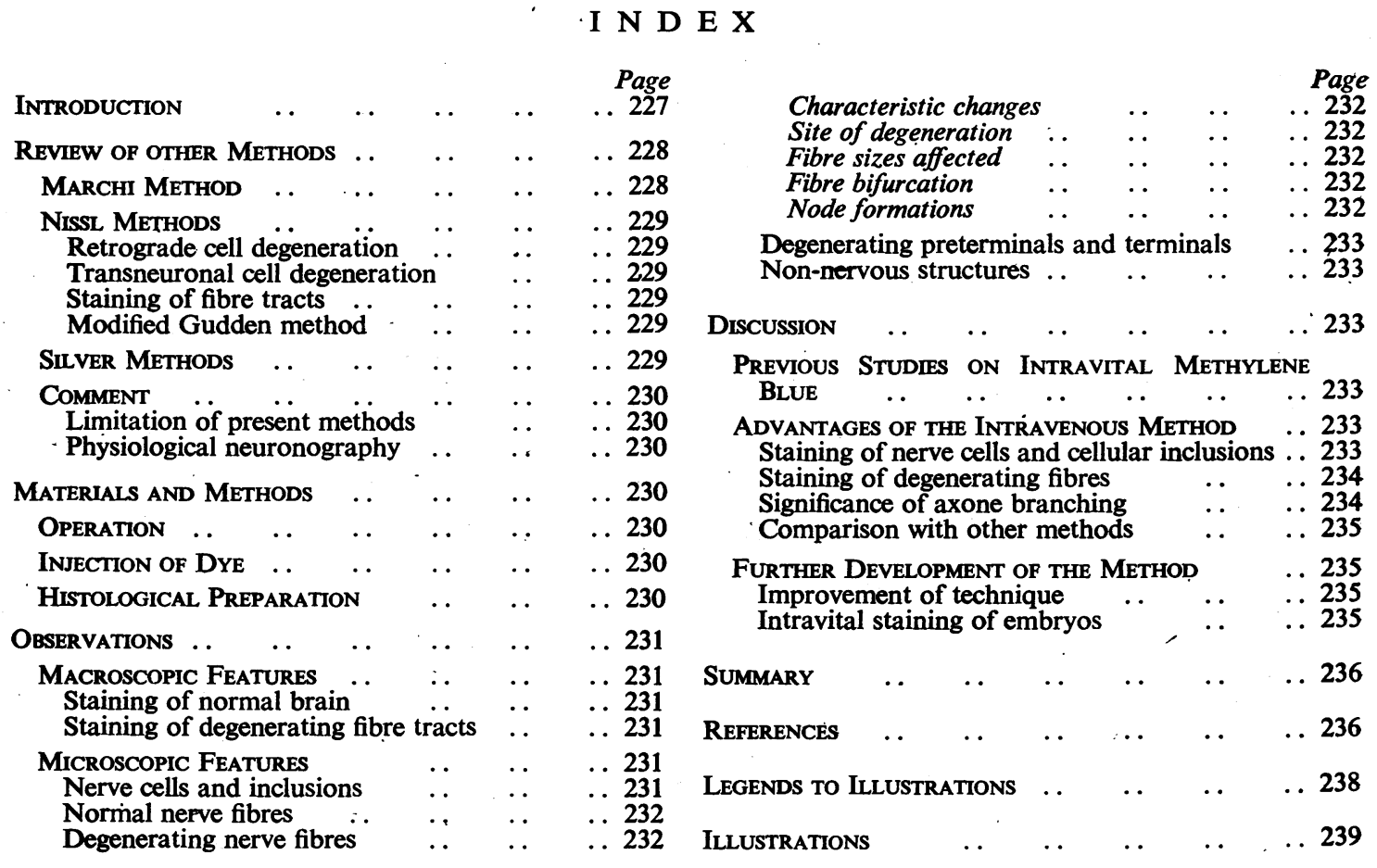

\section{Introduction}

The anatomical connexions of many of the complex fibre pathways in the brain and spinal cord still remain to be determined. Perhaps the most effective means of precisely defining these connexions is to map out, in histological sections, the degeneration of nerve cells and nerve fibres resulting from experimental or selective clinical lesions. Investigations of this nature have been dependent upon a surprisingly small range of

- Read in part before the Anatomical Society of Great Britain Bristol, June 28, 1948, and The Research Fellows' Society, Montrea Neurological Institute, September 23, 1948. neuro-histological techniques capable of demonstrating such degenerative changes. It is well recognized, moreover, that even these few methods, valuable as they are, suffer from certain inadequacies and involve technical difficulties which limit their usefulness to the experimental neurologist. Any new technique, therefore, which shows promise of. being adaptable for this purpose is worthy of consideration.

In previous reports (Feindel, Sinclair, and Weddell, 1947, 1948) attention was drawn to the advantages for investigating the nervous system of a staining technique which is based upon the intravenous perfusion of methylene blue into an 
anæsthetized animal, and which permits a wide application of this dye as an intravital stain selective for nervous tissue. This technique has now proved of value in a number of studies on the peripheral and autonomic nervous systems, including the neural patterns in skeletal muscle, cornea, skin, and epiglottis (Feindel, 1948); the neural basis of pain sensibility in deep somatic tissues (Feindel, Weddell, and Sinclair, 1948) ; the innervation of the iris (Hinshaw, Feindel, and Weddell, 1948), and the nerve supply of blood vessels (Millen, 1948).

In regard particularly to the central nervous system, the intravenous method makes possible the perfusion and uniform staining in vivo of the entire brain, which may then be removed and prepared for microscopic examination as frozen or paraffin sections. With this method it has already been possible to demonstrate in the normal brain cytological details such as boutons terminaux on cortical ganglion cells and on mitral cells in the olfactory bulb, which can be impregnated only with difficulty (Meyer and Meyer, 1945; Gibson, 1937) by specialized silver techniques.

More recently (Feindel and Allison, 1948), it was found that the intravenous methylene blue method is capable of giving a striking picture of nerve fibre degeneration following experimental lesions of the brain. In rabbits perfused with a relatively small quantity of concentrated solution of the dye five days after enucleation of one eye, degenerating fibres in the optic nerve and contralateral optic tract are easily recognized macroscopically by their intense and metachromatic staining, which is conspicuously different from that of normal fibres. On microscopic examination the degenerating axis cylinders show, in addition, morphological changes such as blistering and fragmentation which render them clearly distinguishable from the normal.

These two main features of intravital methylene blue, the selective staining of normal nerve tissue and the differential staining of degenerating neuronal elements, endow the intravenous technique with considerable potentialities as an experimental method for anatomical research on the central nervous system. The purpose of this report is to discuss these potentialities on the basis of results obtained so far from studies of experimental degeneration in the optic system of the rabbit. It should be emphasized that the actual method used at the present stage of our investigations, although satisfactory for some purposes, is not yet sufficiently critical for all types of experimental material from the central nervous system, and, indeed, it is still in the process of modification and improvement.

\section{Review of Other Methods}

In order to evaluate the possible advantages of the intravenous method, it will be compared at many points throughout this paper with experimental methods previously developed for investigating the anatomy of central fibre pathways. Some aspects of these techniques have been discussed at length (Walker, 1938 ; Fulton, 1943 ; Clark, 1945) but no review which considers, for example, the recently developed silver technique for demonstrating terminal degeneration (Glees, 1946), has yet been made. It therefore seems desirable to outline here the main features of these other techniques.

Marchi Method.-A great part of our basic anatomical knowledge of the pathways in the central nervous system has been provided by the use of the technique introduced by Marchi and Algeri (1885), which depends upon the observation that the products of degeneration of myelin sheaths can be stained black by osmic acid, while staining of the normal myelin can be prevented by preliminary treatment with a chromic salt. The distribution of the degenerating tracts, if their fibres are closely packed, can be readily outlined macroscopically, and can be traced in considerable detail by microscopic examination of serial sections. A serious limitation of the method is its deficiency in demonstrating degeneration in non-myelinated or finely myelinated fibres, for fibres of this size may constitute a large proportion of such important pathways as the spinoe thalamic tract (Håggqvist, 1936), the medullary pyramidal tract (Lassek and Rasmussen, 1939), many of the pathways projecting to and from the hypo thalamus (Fulton, 1943), and the projections fron the cortical suppressor areas to the basal ganglia (Glees? 1944). Indeed, by the widespread use of the Marchi technique, neurologists have perhaps tended to overlook the significance of small myelinated and non-myelinated fibres in many tracts of the central nervous system.

In addition, since even myelinated fibres may become divested of their myelin sheaths some distance before they end, as, for example, in the case of the collicular fibres of the optic system, their terminations cannot be conclusively determined by this method. Neither can terminal fibres be distinguished with assurance from fibres of passage. Moreover, myelinated fibres may frequently give off small myelinated or non-myelinated collaterals (Ramón y Cajal, 1928) which may not be rendered visible by the Marchi stain.

A further inherent disadvantage of the Marchi reaction is that the course of the degenerating fibres is indicated mainly by granular tracks of myelin débris and not by actual staining of the intact axis cylinder. Thus it is almost impossible to observe the site and extent of axone branching or to estimate the size of degenerating fibres.

Finally, despite numerous improvements and modifications (Mettler, 1932 ; Swank and Davenport, 1934, 1935; Glees, 1943) the method still remains, from a technical standpoint, a highly variable and capricious one. It requires great care in order to obtain specific staining of degenerating fibres and to avoid pseudo-Marchi 
precipitation, which is capable of simulating degeneration in apparently normal fibre tracts.

\section{Nissl Methods}

Retrograde Cell Degeneration.--It was first noted by Nissl (1892) that when an axone is cut its nerve cell undergoes characteristic changes, including at first chromatolysis, followed by atrophy and glial replacement. This process of retrograde cell degeneration provides, in certain situations, an accurate means of tracing the origin of fibre tracts, but the method has several important limitations.

The cells from which a tract is derived must be compactly grouped so that the zone of atrophy can be recognized in histological sections. This arrangement seems to hold particularly for the thalamic nuclei which send projections to the cerebral cortex, and the method has proved of great value in experienced hands for the study of thalamo-cortical connexions, both in experimental (Clark, 1932; Walker, 1938) and in clinica! material (Meyer, Beck, and McLardy, 1947). The method is not a particularly sensitive one and is of little use for studying fibre tracts, such as the cortico-cortical association pathways, whose cells of origin are more diffusely arranged. Furthermore, retrograde cell changes may not necessarily occur at the same time interval in neurones in various parts of the central nervous system, and the optimum period must be determined for each fibre system studied. In addition, some nerve cells show little demonstrable alteration after a lesion (Walker, 1938), and the cell bodies of certain neurones, for example in the supraoptic nucleus, normally have an appearance which simulates chromatolysis. The occurrence of axone bifurcation in central fibre tracts may also complicate the situation, since section of a collateral branch may cause little or no change in the parent cell (Ramón y Cajal, 1928).

Transneuronal Cell Degeneration.-The process of transneuronal, or better, trans-synaptic degeneration can also be studied by Nissl stain. Since this phenomenon depends upon the fact that a nerve cell becomes atrophied when the fibre ending on it has degenerated, it provides a basis for defining the site of termination of nerve fibres. Unfortunately, trans-synaptic changes are known to occur in relation to only a few neuronal systems, and seems to be related to the rather special circumstance that each nerve cell concerned is entirely dependent for its afferent influence upon its contiguity with a single terminal fibre.

The method has been applied successfully to studies on fibre termination in the lateral geniculate body of monkey (Minkowski, 1920 ; Clark and Penman, 1934), and man (Clark, 1942).

Staining of Fibre Tracts.-The basic dyes used in the various modifications of the Nissl technique are taken up only by the cell bodies and the immediate processes of neurones. Since neither the myelin sheaths nor the axis cylinders of normal or degenerating fibres are stained, the method is not primarily applicable for studying the course of fibre paths. Some compact fibre tracts such as the prefronto-pontile (Arnold's) bundle may, however, often be traced in thickly cut celloidin sections stained with the Nissl technique, by following the track of dense gliosis and increased vascularity resulting from degeneration (Meyer and others, 1947).

Modified Gudden MeThod.-If experimental lesions are made in the brains of young or newborn animals, the retrograde atrophy and cell loss takes place more rapidly than in older animals, and eventually leads to the formation of a glial scar which grossly indicates the localization of the lesion. This method, originally introduced by Gudden in 1870 (see Fulton, 1943), has had only moderately successful use. Recently, however, Brodal (1940) has made an intensive study of the method, and by adopting a shorter post-operative survival time has found it possible to utilize the marked early cell changes while eliminating the undesirable distortion of the later gliosis. This modification appears to make the method more sensitive, and in spite of its disadvantages, such as the difficulties of producing accurately placed lesions in the brains of young animals, it has proved of value in studies of the olivocerebellar connexions and the anterior commisure (Brodal, 1940, 1948).

Silver Methods.-Silver impregnation techniques have been used for many years by the Spanish school of histologists for demonstrating degenerative changes in nerve fibres. The enlargement and deeper degree of staining which terminal boutons show during degeneration have been utilized by Hoff (1935), Gibson (1937), and others for the purpose of anatomical localization of fibre termination. However, the successful impregnation of boutons, particularly in nervous tissue from supra-spinal levels, is a difficult technical feat and for a number of reasons the results based upon the interpretation of degenerative changes in boutons terminaux have not been accepted as entirely conclusive by all workers. Fulton (1943) has given an excellent review of this somewhat controversial question. More recently, a silver method developed by Glees (1946), which demonstrates not only boutonal endings but also the more conspicuous preterminal and terminal parts of degenerating nerve fibres, has proved invaluable as a means of studying the ultimate distribution of central fibre tracts. Although this method overcomes many deficiencies of the Marchi technique, in that it gives evidence of the precise terminal distribution of nonmyelinated as well as myelinated degenerating fibres, its application also presents a number of difficulties. Terminals in normal tissues are notoriously subject to variation (Phalen and Davenport, 1937 ; Minckler, 1942). For this reason, areas in which it is expected that degeneration will be found must be carefully compared with corresponding normal control areas. Furthermore, slight alterations in the picture of terminals must be disregarded as being possibly within the range of normal variation. Only well-marked changes can be accepted as conclusive evidence of experimental degeneration. The time limits during which such changes are optimally 
demonstrated by silver impregnation are quite narrow, usually from 4 to 7 days postoperatively, and this factor restricts the range of clinical autopsy material which can be studied.

These features, together with the fact that the technique itself, like most metallic methods, is painstaking and time-consuming, tends to limit its scope to tracts which terminate in relatively small topographical areas. The application of such a method also requires both a high degree of technical skill for the preparation of reliably impregnated sections, and an intimate experience of the experimental material in order to interpret the histological findings. It has been applied with valuable results to studies in experimental animals on the termination of the optic tract (Glees and Clark, 1941), the cortico-striate connexions (Glees, 1944), and the olfactory tract (Clark and Meyer, 1948). In human material after leucotomy, it has been used to define the corticofugal connexions of the frontal lobe (Meyer and Crawford, 1948).

\section{Comment}

Limitation of Present Methods.-In summary, it may be stated that each of the above-mentioned techniques has its own particular advantages. All except the silver technique have been exploited for many years. The fact that so little (and often conflicting) information is available about the detailed neuro-anatomy of many important pathways in the central nervous system is in itself evidence of their limitations. It is surprising, for example, that the anatomical connexions of the temporal lobes are largely unknown (Walker, 1938; Fulton, 1943) although, on physiological and psychological grounds, their role in the higher mental organization of the individual is undoubtedly of the utmost importance (Penfield, 1946 ; Clark, 1948).

Physiological Neuronography.-Although not a histological tech ique, the method of physiological neuronography should be briefly mentioned. This technique (see McCulloch, 1944) depends upon the mapping out of large electrical potentials propagated as a result of the excitation of a local area of the brain by application of strychnine and has recently brought about advances in experimental neurology so remarkable that they have opened up a completely new approach to this field of study. However, in most cases, the anatomical basis for the nervous pathways along which these potentials travel still remains to be defined.

The results which have been obtained so far by the use of intravenous methylene blue on the central nervous system suggest that this method, if it is found to give consistently satisfactory results, may be' a useful supplement to the experimental anatomical methods. now available.

\section{Material and Methods}

Operation.-Young male and female rabbits weighing 1 to 1.5 kilogrammes were used in the present study. Enucleation of one eye was previously selected (Feindel and Allison, 1948) as a convenient control lesion for evaluating the staining method because the operative trauma is entirely extracranial and the anatomical features of the primary optic pathways are fairly well established (Clark, 1942 ; Fulton, 1943).

In each of eight animals one eye was removed under ether anæsthesia, with care to prevent traction on the optic nerve. Hæmostasis was secured by warm saline packs. Penicillin-sulphamezathine powder was then insufflated into the orbit and the lids closed by several interrupted silk sutures. The wounds were examined at autopsy and without exception were found to be free from infection and post-operative hæmorrhage. In two more animals, in addition to the removal of the eye, a unilateral olfactory tract section was made through an orbital approach. Normal brains from ten animals which were injected for the study of tissues other than the central nervous system were also available for comparative studies.

Injection of Dye.-At intervals varying from twenty-four hours to twenty days after operation the animals were lightly anæsthetized with intravenous nembutal (35 mg. per $\mathrm{kg}$. of body weight) and given methylene blue (supplied by British Drug $\frac{O}{\mathrm{D}}$ Houses Ltd.), in 0.9 per cent. physiological saline, by을 $z$ the intravenous drip technique previously described (Feindel, Sinclair, and Weddell, 1947).

However, in the present investigation, a more concentrated solution of the dye, up to 2.5 pero cent., was used in order to decrease the volume of:fluid injected and to obviate the risk of cerebral œdema. A large dose of the dye (300 to $500 \mathrm{mg}$. per kg. of body weight) was deliberately administered during the early experiments, but it is now clear that much smaller dosages may be adequate. The injection was regulated at 2 to 6 drops per minute, depending upon the concentration of the dye solution, and was usually prolonged for one to three hours. At the end of this time the animals were killed by a rapid overdose of a few c.cm. of the dye, or by an overdose of nembutal, or, in a few cases, by section of the medulla.

Histological Preparation.-The brain was then removed and immersed in a chilled solution of 6 per cent. ammonium molybdate, made up in 0.9 per cent. saline as suggested by the work of Cole (1946). Penetration of the molybdate into the brain tissue, which ensures uniform fixation of the dye, will occur to a depth of not much more than one centimetre. Sections of the brain were therefore cut at rather less than that thickness with a sharp razor blade, taking great care to 
avoid distorting the tissue. Adequate fixation of the dye can be assured by keeping the tissue slices in the refrigerator at $0^{\circ}$ to $2^{\circ} \mathrm{C}$. for a period from two to sixteen hours, varying with the size of the specimen. After thorough washing in several changes of chilled saline ( 0.9 per cent.) for a period of fifteen to twenty minutes, the brain sections were kept in 10 per cent. neutral formol-saline for a period which, it was found, should not exceed three days. Frozen sections could then be cut and, after dehydration and clearing in xylol, mounted in neutral balsam.

Most of the tissue studied, however, was washed after formalin fixation and dehydrated in alcohol, using generous quantities and rapid changes to eliminate loss of dye. Some blocks were then cleared in xylol and embedded in paraffin, but it was later found that embedding by the double celloidin-paraffin method of Peterfi (see Romeis, 1924) gave superior preparations. The tissue blocks, when embedded, are a deep blue colour. They may then be sectioned and, without further staining, taken directly through xylol, alcohol and xylol, and mounted in neutral balsam.

The reagents most likely to dissolve out the stain are the ethyl alcohol and the solution of celloidin in methyl benzoate. The tissue blocks should be taken through these stages as rapidly as possible. Mounted sections, in spite of exposure to intense light for photographic purposes; are resistant to fading for many months.

\section{Observations}

\section{Macroscopic Features}

Staining of Normal Brain.-On removal of the calvarium the surface of the brain is usually pale blue but gradually darkens on exposure to air, until the entire brain appears deep blue in colour (Fig. 1). Some areas darken more rapidly than others, and in the early stages this gives a blotchy appearance to the cortex, with pale areas standing out, as for example, in the temporal poles of the brain illustrated in Fig. 2.

When the fresh brain is sliced, the "blueing" is seen to be confined to the external surface, although the cut surface soon becomes blue in turn. Adequate immersion in molybdate solution brings about a more even blueing of the dye throughout the entire block of tissue.

Grey matter is stained more deeply than white matter, so that normal fibre tracts, such as the corpus callosum and the internal capsule, remain pale (Fig. 3).

Staining of Dégenerating Fibre Tracts.Degenerating fibres take up the stain as intensely as grey matter and exhibit, in addition, a distinct purplish tinge. This deeper and metachromatic staining permits the ready identification of the degenerating optic nerve and outlines the bundle of crossed degenerating fibres in the optic tract (Figs. 1, 2 , and 3). In the two instances in which an additional lesion in the olfactory tract was made, the definite purplish colour of the degenerating fibres provided sufficient contrast with the deep blue of the surrounding normal cortex to mark out by naked eye examination the distribution of olfactory fibres in the piriform area.

A further observation is that the differential staining of the degenerating fibres loses none of its distinctness as late as twenty days after removal of the eye (Figs. 2 and 3). Weddell and Glees (1941), injecting methylene blue locally, showed that degenerating fibres in cutaneous nerves are not stained by the dye later than fourteen days after experimental section. This difference may be due in part to the more rapid removal of degenerating neuronal products in the periphery, as compared to the central nervous system.

Microscopic Features.-The prepared sections of the brain have much the same appearance to the naked eye as sections stained by the ordinary Nissl technique. On microscopic examination the most outstanding features are the staining of the cell bodies and immediate processes of the neurons, the slight degree or absence of staining of normal fibre tracts in most regions, and the conspicuous differential staining of degenerating nerve fibres.

Nerve Cells and InClusions.-Cytoarchitectonic differences in basal ganglia and cortical areas are sufficiently clear to allow their satisfactory identification, as, for example, the retrosplenial cortex shown in Fig. 9. Indeed, because there is some staining of matrix as well as cell bodies, differences between adjacent cell masses and layers are often more marked than in sections stained by the standard Nissl techniques (Fig. 29). Moreover, in many cases, satisfactory analytic staining of normal neurones clearly showing the finest ramifications of their axons and dendrites, as well as their nuclei, are obtained.

Usually the cytoplasm of neurones appears a homogeneous, clear, light pastel blue colour. In certain situations, however, a large number of fine blue granules are scattered throughout the perikaryon and along the axone, as shown in Figs. 27 and 28 . In some cells there is superimposed upon this fine granulation a mass of coarse, darkblue spherules, often inter-connected and closely packed about the nuclear region of the cell (Fig. 27). 
The possible significance of these structures will be discussed below.

Normal Nerve Fibres.- Normal nerve fibres are usually unstained but may occasionally be stained a green-blue colour. In some regions, for example the pons, the fibres show a smooth, evenly stained, wire-like appearance (Fig. 15), while in other areas, such as the internal capsule, they may sometimes present smooth ovoid varicosities (Fig. 16).

Degengrating Fibres.-Degenerating fibres, on the other hand, are distinguished readily from normal fibres by their intense purplish shade of staining and by the morphological changes described below. These features render them conspicuous even under low-power magnification so that their main course and distribution may be rapidly traced in serial sections (Figs. 4, 5, and 10).

Under high magnifications, the degenerating fibres, with their purple staining (Figs. 7 and 8) and distorted outline (Figs. 11, 12, 13), are strikingly different from normal fibres (Fig. 15).

Characteristic Changes.-Many stages of fibre degeneration are present five days after the experimental lesion. The change in staining reaction probably takes place early, since many fibres with minimal distortion in outline have a distinct purple colour. This was suggested by studies in the peripheral nervous system where metachromasia occurs very soon after section of a cutaneous nerve (Weddell and Glees, 1941). Prominent varicosities appear at intervals along the swollen axis cylinders, and at a later stage these varicosities enlarge into round vesicular masses strung along the irregular swollen axones (Figs. 21, 22). The ballooned vesicles may reach an astonishing size and often appear hollow or reticulated (Figs. 12, 13). A characteristically blistered and purple axone is shown in Fig. 7. Finally, axones and vesicles lose their solid, densely stained appearance, become more lightly stained and mesh-like, and eventually disintegrate into coarse, irregular fragments. The vesicles often persist as isolated spherules with no apparent axonic thread connecting them (Fig. 13). Throughout all stages of degeneration the metachromatic staining is maintained, even for the fragments and granules of axones. It is of interest that these morphological changes in degenerating fibres as demonstrated by intravital methylene blue are almost identical with those described by Cajal (19.28), who used the reduced silver nitrate technique, for many parts of the central nervous system including the primary optic pathway.
Site of Degeneration.-Five days after the lesion degenerative changes appear, in general, to be most advanced toward the termination of the optic tract, that is, in areas most remote from the lesion. This observation conforms with those obtained by Meader (1939), using the Marchi technique.

Fibre Sizes Affected.-Even making allowance for the degenerative changes, considerable variation of axone size is demonstrated in the optic tract. The degeneration at five days appears to affect the entire spectrum of fibre sizes, although it is more pronounced in the larger fibres. Some medium and small fibres may show granular fibrillated axones, sometimes without the formation of vesicles. But a number of individual fibres of the very finest diameter show ovoid swellings strung along an axone undergoing early fragmentation (See Figs. 6, 8, 11, 12, 13).

Again, in a general way, no sorting out of fibre sizes seems to occur at the level of the lateral geniculate body, and the fibres coursing on to the mid-brain are not necessarily those of the smallest diameter (Fig. 14). It is obviously necessary, however, for this observation to be substantiated by further study, particularly of material at shorter postoperative intervals and after minimal retinal lesions. The wide range of fibre size which is apparent in the material is illustrated in Figs. 6,0 11 , and 14 and no doubt provides a morphologicalo basis for the differences of conduction velocity in the optic fibres which have recently been summarizedo by O'Leary (1944).

Fibre Bifurcation.-As in the peripheral nervous system, the intravenous methylene blue stains the individual degenerating axis cylinders. For this reason degenerating fibres may be traced for considerable distances. The precise course and direction of the axones are therefore readily determined (Figs. 6, 11). Collateral fibres are boldly outlined, for example, where they run towards the dorsal nucleus of the lateral geniculate body (Figs. 5, 11, 14), and the axone branching where these collaterals originate can usually be found (Figs. 10, 12, 14, 19, 20).

Node Formation.-At the site of axone branching a definite node-like formation may be seen, which often takes the form of a cuff placed just at the angle of the dividing axone (Figs. 19, 20), a picture very similar to that obtained by methylene blue and silver stains in the periphery. Constrictions may also be seen along the course of axis cylinders, and these too are suggestive of nodal structures (Fig. 17). It is of some interest, as Cajal (1928) observed with 
silver stains, that swelling of the axoplasm during degeneration may first take place on either side of such a nodal constriction (Fig. 17). Further evidence for the existence of nodes in the central nervous system has been the presence at intervals along the purple degenerating axone of cuffs which are distinguished by their intense degree of staining and their green-blue coloration (Fig. 18). Although nodes on normal fibres in the central nervous system have been beautifully figured and described by Cajal (1911, 1928), for example, in the optic nerve and spinal cord, the present-day scepticism concerning their existence has prompted us to re-emphasize this finding in the light of the present observations (Allison and Feindel, 1948).

\section{Degenerating Preterminals and Terminals.-} The preterminal portions of the degenerating fibres, as well as the actual terminal boutons, may be stained both in the lateral geniculate body and in the midbrain. The preterminals may appear as strings of solid or vesicular beads among the ganglion cells upon which they terminate (Figs. 8 and 23). The normal terminals (Fig. 24) are small swellings which, at one level of focus under high magnification, appear as ring formations on the surface of the cells. Degenerating terminals take the form of enlarged solid plaques, which stain deeply with methylene blue (Figs. 25, 26). 'The appearance of the normal as well as the degenerating boutons terminaux corresponds closely to the picture obtained by the silver technique of Glees (Meyer and Meyer, 1945) or the double impregnation method of Hortega (Gibson, 1948). It has already been pointed out that the critical staining of such fine terminals by intravenous methylene blue may be related to the fact that the stain is applied to living nervous tissue (Feindel, Sinclair, and Weddell, 1947).

NoN-NERVous StruCtURes.-Brief mention may be made of non-nervous structures stained by the same technique. Cerebral and intracerebral blood vessels are satisfactorily demonstrated. With heavy doses of dye, it is also possible to obtain staining of neuroglial elements. Thus the cell-bodies and processes of astrocytes, particularly in the region of small intracerebral blood vessels, may take up the dye. In addition, ependymal cells of the ventricular lining may stain selectively so that their unipolar processes can be seen extending into the cerebral tissue (Fig، 30).

\section{Discussion}

Previous Studies on Intravital Methylene Blue.-It should be noted that the general features of intravital methylene blue technique have by now become well established by numerous studies on the peripheral nervous system, which have been summarized by Dogiel (1926), Schabadasch $(1935,1936)$, and Weddell and others (1940). The fact that degenerating fibres in the periphery may be differentially stained by intravital methylene blue has been recognized for some time and utilized in a number of studies, including the innervation of the neuromuscular spindle (Hines and Tower, 1928), the origin of the fibres supplying Pacinian corpuscles in the mesentery (Sheehan, 1933), and the distribution and pattern of cutaneous nerve fibres and endings in experimental animals and man (Weddell, 1945). The early stages of degeneration in cutaneous nerve fibres have been studied in detail, using both vital methylene blue and silver methods, by Weddell and Glees (1941).

It is of historic interest that Ehrlich (1886), in his original paper on the use of methylene blue as a stain for living nerve tissue, described staining of nerve fibres in the medulla and cerebrum as well as pericellular networks of fine nerve fibrils in relation to cortical ganglion cells. Cajal (1911) placed great importance on methylene blue as an analytic stain for studies on the normal brain, and the many finely executed illustrations in his classic textbook indicate the remarkable success he achieved in applying the method. In his studies of nerve degeneration, in both the peripheral and central nervous systems, however, Cajal (1928) relied almost exclusively upon silver impregnations, dismissing the methylene blue method of Ehrlich because of his early observation (Cajal, 1896) that the results were uncertain and obtained only with difficulty. Reference to any other serious attempt to study fibre degeneration in the central nervous system by vital methylene blue has not been found (Feindel, 1948).

Advantages of the Intravenous Technique.-Many of the advantages and possible developments of the intravenous method which have been discussed with particular reference to the peripheral nervous system (Feindel, Sinclair, and Weddell, 1947) also apply to the technique as used for experimental studies on the central nervous system. Two main features are evident from the results described above. In the first place, almost the entire neurone - cell-body, cytoplasmic inclusions, axis cylinder, and terminals - may be demonstrated. Secondly, degenerating axones, preterminals, and terminals are conspicuously differentiated from normal axis cylinders.

Staining of Nerve Cells and Cellular INCLUSIONS.-The staining of nerve cells as a 
whole implies that the method may be developed as an analytic stain for normal central nervous tissue, serving to some extent as a substitute for the uncertain Golgi technique. Reference has already been made to Cajal's use of the method for this purpose, and similar brilliant results have been obtained more recently by Polyak (1941) in his well-known studies on the neuro-cytology of the retina. Many other structures of the normal neurone, such as the nodes of the axis cylinders and the peri-cellular terminals, are demonstrated.

The staining of granular inclusions within- the cytoplasm of normal nerve cells, which show considerable resemblance in distribution and character to mitochondria and Golgi apparatus, is of some interest. Methylene blue has been used not only as a supravital stain for mitochondria and Golgi apparatus (Worley and Worley, 1943) but also as a stain for such intracellular substances as ribonucleoprotein (Wislocki and Dempsey, 1948). These observations suggest that the intravenous method, by virtue of being applied to living nervous tissue, may possibly be elaborated into a cytological technique for studying nerve cell inclusions. Since it is well known that cytoplasmic inclusions are intimately related to the metabolism and activity of the cell, the method may perhaps also be utilized as an indicator for the functional activity of different nerve cell groups. Indeed, Ehrlich (1885) was led at first to use methylene blue, not because of its histological value, but for indicating the level of metabolic gradients in different tissues of the living animal. Moreover, a number of most suggestive observations have been made on the pharmacological antagonism of intravital methylene blue and acetylcholine (see, for example, Cook, 1926) and it is not improbable that the vital staining of fine nervous terminals may be related to the high content of acetylcholine present in association with nerve endings (Nachmansohn, 1939). Further work along these lines is clearly indicated.

Staining of Degenerating Fibres.-The ready identification of degenerating fibres by their metachromatic purple staining and by their characteristic vesiculation and swelling is also a feature of fundamental importance. The feasibility of identifying degenerating fibre tracts in macroscopic sections is of value in that it may provide an indication of the main areas to which a fibre system is distributed. Thus, it may serve as a useful complementary technique to silver methods, which are impractical for exploring very extensive regions of the brain. In microscopic sections, the individual degenerating axones can also be identified not only in their main course but even towards their terminations.

Significance of AxoNe Branching.-The method provides a means for noting axone bifurcation and for tracing collateral fibres, for example, where they sweep from the optic tract into the dorsal nucleus of the lateral geniculate body. The site and mode of axone branching in the central fibre tracts is a subject which has $\vec{?}$ received remarkably little direct study, although. it is a neural mechanism which may provide a great degree of flexibility for fixed anatomical $\frac{\mathrm{C}}{\mathrm{a}}$ pathways in the central nervous system. Thereby, functional connexions may be established by a single ganglion cell with different regions of the central nervous system which are widely separated.

The occurrence in the peripheral nervous system of such axone branching, which allows one nerve cell to have endings in two widely separated areas of skin, is implied by the work of Adrian and others (1931), and the significance of this axonal arrangement in providing an anatomical explanation of the mechanism of referred pain has recently been emphasized (Sinclair, Weddell, and Feindel, 1948).

Sherrington (1892) noted the incidence of geminas N or bifurcating myelinated fibres in various parts of the brain and spinal cord. Cajal (1911) confirme Nansen's classical studies on the division of dorsa\$ root fibres in the spinal cord, and contributec observations of his own on fibre bifurcation it many regions of the brain stem and in the sub? cortical white matter. O'Leary (1944), with paro ticular reference to the optic system, has recently described the influence which such axone branching may have on the character of electrical responses from central fibre tracts. In the present material, extensive axone division appears to take place at the level of the lateral geniculate body, with some branches coursing towards the dorsal nucleus (Figs. 5, 10, 11, 14) and others running on towards midbrain nuclei. In both regions many axones, before their final termination, also frequently show branching (Figs. 19, 20). Cajal (1911) by the use of Ehrlich's methylene blue method in the rabbit, found axone bifurcation in a small number of fibres in the optic chiasm, one branch passing backwards into each optic tract.

Fibre branching of this nature is obviously of relevance in anatomical studies of the visual patbway, for example, in the determination of the ratio of retinal ganglion cells to optic fibres. Furthermore, such a mechanism may provide an actual anatomical basis for a number of phenomena related to the bilateral representation of the visual pathways, such as macular sparing, which have heretofore been unsatisfactorily explained. 
Comparison With Other Methods.-In a general way, then, the method gives promise of combining some of the advantages of all three main histological techniques at present in use for experimental studies on the central nervous system.

Like the Marchi technique, it gives a highly contrasting picture of the main course of degenerating fibre tracts. It has the additional advantage, which the silver techniques possess, of staining the degenerating axis cylinder independently of the presence of a myelin sheath, so that non-myelinated as well as myelinated fibres may be traced. Again, as in the silver method, the preterminals and terminals, particularly the degenerating boutons terminaux, are demonstrated in relation to the cell bodies of the neurones, thus permitting a precise definition of the terminal distribution of the fibres. Unlike the silver impregnation, however, where the degenerating fibres must often be differentiated by careful observations from a rich background of neuropil, the methylene blue fortunately has an affinity for degenerating fibres while it stains normal fibres only to a slight degree or not at all. This enables the distribution of a smaller number of degenerating fibres to be recognized much more quickly over an extensive topographical area than can be done by the use of silver stains. The method may therefore be applicable to the study of diffusely arranged or sparsely constituted fibre pathways. Moreover, the staining and technical preparation of the material is likely to be less arduous than with the impregnation methods, and, unlike the latter techniques, which must be carried out on frozen sections, the material stained with intravital methylene blue may be embedded and sectioned serially in the ordinary way.

Methylene blue has also been one of the standard basic dyes used for the ordinary Nissl method, and the staining of the cell bodies and cytoplasm of the neurones by the intravenous methylene blue is therefore not surprising. This feature is particularly useful in experimental material in that it makes it possible to ascertain, in the same preparation; the relationship of fibre tracts to groups of ganglion cells, but the potentialities which it may offer for critical demonstration of retrograde or transneuronal cell changes have yet to be determined.

\section{Further Development of the Method}

IMPROVEMENT OF TECHNIQUE.-At present the successful preparation of material depends upon three essential points : (1) the slow perfusion of sufficient dye into the animal to produce staining of the central nervous system ; (2) the uniform oxidation and fixation of the dye ; and (3) the histological fixation of the tissue itself. Since further investigations on these points are still in progress, only brief mention will be made of them.

The determination of the minimal dosage of the dye is of some relevance because of its chemical or pharmacological toxicity, which may, for example, be responsible for occasional aberrant subcortical degenerating fibres noted in some of our preparations. The occurrence of these to any extent would obviously make the method less critical.

With the present method of cutting the fresh brain into slices and immersing these in ammonium molybdate solution, uniform oxidation and fixation of the dye can usually, but not always, be achieved. This is the main defect of the technique at present since the distinct picture of degeneration visible macroscopically (Figs. 1, 2, 3) is not always transferred to microscopic sections. Ammonium molybdate, while one of the most satisfactory agents for fixing the dye (Bethe, 1895) (that is, for combining with the dye to form a compound relatively insoluble in alcohol) has two disadvantages : it is a poor tissue fixative, and it cannot be used in combination with the usual tissue fixatives because it forms precipitates with them. Although the technique used here has circumvented these difficulties, they are probably best overcome by adopting intravascular perfusion of ammonium molybdate for fixing the dye, a method which has already been used successfully, for example, by Hines and Tower (1928).

Many of the procedures recommended for intravital methylene blue staining have become overwhelmingly complex, and a careful re-evaluation of the factors which tend to give more specific staining has been made by Heller, Thomas, and Davenport (1947) in relation to the supravital immersion technique. It is of interest to note that the optimum conditions they suggest, such as oxygenation and buffering of staining solutions, the use of solutions at body temperature, and the addition of essential ions and dextrose to the staining solution, are conveniently met by introducing the dye slowly into the blood stream of the living animal.

INTRAVITAL StaINING of EMbryos.-In these studies on the central nervous system, methylene blue has passed readily through the so-called blood-brain barrier, and in connexion with this a further development of the technique should be mentioned. Although earlier work (Goldmann, 1909 ; Wislocki, 1920, 1921) has shown that colloidal dyes, such as trypan blue, pass from the maternal blood only in sufficient quantities to stain the embryo slightly or not at all, the prolonged 
perfusion of concentrated solutions of methylene blue into the pregnant animal has given distinct staining of embryos in rabbits and guinea-pigs (Feindel, 1948). This aspect of the technique may prove of considerable value in neuroembryological studies.

\section{Summary}

The possible applications of intravenous methylene blue for experimental studies on the central nervous system are considered. The method offers the advantage of staining most parts of the normal neurone-cell-body, inclusions, axis cylinder, and terminals-and gives in addition a differential staining of degenerating axones, preterminals, and terminals. The site and mode of axone bifurcation can be readily studied, and the significance of this, particularly in the optic system, is discussed. Nodal structures on axones in the central nervous system are clearly demonstrated. The technique is compared to the' other methods available for studying degeneration in the central nervous system. A few developments of the method, including its use for neuroembryological studies, are outlined.

This work was supported by an expenses grant to one of us (G.W.) from the Medical Research Council. W.H.F. wishes to acknowledge personal grants from the Medical Research Council and from the Carnegie Research Fund administered by the Rhodes Trustees. A.C.A. is grateful for financial support from the Nuffield Fluid Research Fund. The authors are grateful to Professor W. E. Le Gros Clark, F.R.S., for his stimulating interest in this work, and to Mrs. Margaret Meyer for her experienced criticism on many points. Mr. A. W. Dent gave helpfưl technical assistance.

\section{FEFERENCES}

Adrian, E. D., Cattell, McK., and Hoagland, H. (1931). J. Physiol., 72, 377.

Allison, A. C., and . Feindel, W. H. (1948). (In the press).

Bethe, A. (1895). Archiv. mikr. Anat., 44, 579.

Brodal, A. (1940). Arch. Neurol. Psychiat. Chicago, 43, 46 .

-(1948). J. Comp. Neurol., 88, 157

Clark, W. E. Le Gros (1932). Brain, 55, 406.

-(1942). Physiol. Rev., 22, 205.

(1945). "The Tissues of the Body." 2nd Edit. Oxford University Press.

$$
\text { (1948). Lancet, 2, } 353 .
$$

291.

$\overline{\text { Cole }}$, and Meyer, M. (1948). Brain, 70, 304.

Cole, E. C. (1946). Stain Tech., 21, 63.

Cook, R. P. (1926). J. Physiol., 62, 160.

Dogiel, A. S. (1926). In "Enzyklædie der Mikroskopischen Technik," R. Krause. Third Edit. Berlin. Urban and Schwarzenburg. pp. 1390-1414.

Ehrlich, P. (1885). Zbl. med. Wissenschaft, 23, 113.

-(1886). Biol. Zbl., 6, 214.

Feindel, W. H. (1948). "A Study of Neural Patterns by the Aid of Intravital Methylene Blue." D.Phil. Thesis. University of Oxford.
Feindel, W. H., and Allison, A.C.(1948). Science, 107,429. , Sinclair, D. C., and Weddell, G. (1947). Brain. $70,495$.

$\longrightarrow,-(1948) . \quad$ Nature, 161, 318.

- Weddell, G., and Sinclair, D. C. (1948). $J$. Neurol. Neurosurg. Psychiat., 11, 113.

Fulton, J. F. (1943). "Physiology of the Nervous System." Second Edit. New York and London. Oxford University Press.

Gibson, W. C. (1937). " McClung's Handbook of Microscopical Technique." Second Edit. London. Oxford University Press. pp. 481-488.

-(1948). (Personal communication.)

Glees, P. (1943). Brain, 66, 229. (1944). J. Anat., 78, 47.

(1946). J. Neuropath. and exp. Neurol., 5, 54

_, and Clark, W. E. Le Gros (1941). J. Anat., 75, 295.

Goldmann, E. F. (1909). Beit. z. klin. Chir., 64, 192. Håggqvist, G. (1936). Z. mikr-anat. Forsch., 39, 1.

Heller, R. E., Thomas, R. W., and Davenport, H. A. (1947). Stain Technol., 22, 111.

Hines, M., and Tower, S. (1928). Johns. Hopk. Hosp. Bull., 42, 264.

Hinshaw, G. R., Feindel, W. H., and Weddell, G. (1948). In preparation.

Hoff, E. C. (1935). Arch. Neurol. Psychiat. Chicago, 33, 687.

Lassek, A. M., and Rasmussen, G. L. (1939). Arch. Neurol. Psychiat., Chicago, 42, 872.

McCulloch, W. S. (1944). "The Precentral Motoro Cortex." Ed. Paul Bucy. Urbana, Ill., University of D Illinois Press. Chapter 8.

Marchi, V. and Algeri, G. (1885). Riv. sper. freniat., 11, 492.

Meader, R. G. (1939). Proc. Koninklijke Nederland Akad. Wettenschappen., 42, 1 .

Mettler, F. A. (1932). Stain Technol., 7, 95.

Meyer, A., Beck, E., and McLardy, T. (1947). Brain, $70,18$.

$\longrightarrow$, and Meyer, M. (1945). J. Anat., 79, 180.

-, and Crawford, J. (1948). Brain (In the press).

Millen, J. W. (1948). J. Anat., 82, 68.

Minckler, J. (1942). Amer. J. Path., 18, 1061.

Minkowski, M. (1920). Schweiz. Arch. Neurol. Psych., 6, 201.

Nackmansohn, D. (1939). J. Physiol., 95, 29.

Nissl, F. (1892). Allg. Z. Psychiat., 48, 197.

O'Leary, J. L. (1944). " The Precentral Motor Cortex," ed. Paul Bucy, Urbana, Illinois. University of Illinois Rress. Chapter 3.

Penfield, W. (1946) Brit. med. J., 2, 639.

Phalen, G. S., and Davenport, H. A. (1937). J. Comp. Neurol., 68, 67.

Polyak, S. L. (1941). " The Retina." Chicago. University of Chicago Press.

Ramón y Cajal, S. (1896). Rev. trim. micrograf., 1, 26. -_(1911). "Histologie du Système Nerveux de l'Homme et des Vertébrés." Paris. A. Maloine. 2 vols.

- (1928). "Degeneration and Regeneration of the Nervous System." London. Oxford University Press. 2 vols.

Romeis, B. (1924). " "Taschenbuch der Mikroskopischen Technik." Eleventh Edit. Munich and Berlin. R. Oldenbourg.

Schabadasch, A. (1935). " Theoretische und experimentelle Studien zur Methylenblaufärburg des Nervengewebes." Gorkij. Staatsverlag.

(1936). Bull. d'Histol. Appl., 13, 5 ; 72 ; 137. 
Sheehan, D. (1933). J. Anat., 67, 233.

Sherrington, C. S. (1892). J. Physiol., 13, xxi.

Sinclair, D. S., Weddell, G., and Feindel, W. H. (1948). Brain, 71, 184.

Swank, R. L., and Davenport, H. A. (1934). Stain Technol., 9, 129. (1935). Ibid., 10, 87.

Walker, A. E. (1936). J. comp. Neurol., 64, 1.

-_(1938). "The Primate Thalamus." Chicago. University of Chicago Press.
Weddell, G. (1945). Brit. med. Bull., 3, 167.

_-_, and Glees, P. (1941). J. Anat., 76, 65.

- - Harpman, J. A., Lambley, D. G., and Young, L. (1940). J. Anat., 74, 255.

Wislocki, G..B. (1920). Contr. to Embryol. (Carnegie Inst.). 11, 45. (1921). Ibid., 13, 91.

_, and Dempsey, E. W. (1948). J. comp. Neurol., 88, 319.

Worley, L. G., and Worley, E. K. (1943). J. Morph., 73, 365 .

(FOR ILLUSTRATIONS SEE PAGES 239-242 INCLUSIVE, AND COLOUR

INSET. DESCRIPTIONS OF THE ILLUSTRATIONS APPEAR ON PAGE 238.) 
All illustrations are of brains of rabbits injected intravenously with methylene blue. Except where otherwise noted, illustrations of microscopic sections are of material showing degeneration five days after removal of one eye.

\section{Plate I.}

FIG. 1.-Whole brain shortly after removal showing the type of staining obtained. The right eye was removed ten days previously. Note darker staining of right optic nerve. . (Approximately $\frac{3}{4}$ natural size.)

FIG. 2.-Enlarged view of optic chiasm, showing darker staining of right optic nerve and left optic tract twenty days after removal of right eye. (Approximately $\times 2$.)

Fig. 3.-Cross-section of another fresh brain twenty days after removal of right eye, showing darker purplish staining of right optic nerve. Note the pale staining of the left optic nerve and the white matter. (Approximately $\times 2$.)

Fig. 4.-Region of lateral geniculate body as seen in microscopic section, showing staining of degenerating fibres five days after removal of contralateral eye. (X 25.)

FIG: 5.-The same section, at higher magnification, showing collateral fibres running at right angles toward the dorsal nucleus of the lateral geniculate body (represented at the lower right of the illustration). $(\times 150$.

Fig. 6.-Another region of the same section showing the variation in size of the degenerating optic tract fibres. $(\times 250$.)

Fig. 7.-A single degenerating fibre, showing the blistering and purple staining of the axon. ( $\times 550$.

Fig. 8.-Degenerating preterminal fibres and nerve-cells in the midbrain. Note the intense purplish staining of the fibres as contrasted to the green-blue of the nerve cells. $(\times 550$. $)$

\section{Plate II.}

Fig. 9.-Cerebral cortex, retrosplenial area, showing typical staining of nerve cells. $(\times 80$.

FIG. 10.-Region of lateral geniculate body showing degeneration of crossed optic fibres. Note, at upper left, collaterals coursing toward dorsal nucleus at right angles to main fibres. At lower right, a Y-shaped bifurcation may be made out. ( $\times$ 75.)

Fig. 11.-Detail from Fig. 10, showing main optic fibres and collaterals. ( $\times 450$.

\section{Plate III.}

FIG. 12.-Degenerating fibres and terminals in the dorsal nucleus of the lateral geniculate body of the side opposite to the lesion. The vesiculation and early fragmentation of the fibres is to be noted. $(\times 625$.

FIG. 13.-Details of degenerating fibres in another part of the lateral geniculate body in the same case. Note the irregularity and swelling of fibres and the isolated axonic balls. $(\times 625$.

\section{Plate IV.}

FIG. 14.-Crossed degenerating fibres in the optic tract skirting the dorsal lateral geniculate nucleus. Note collaterals leaving the tract at right angles to pass into the nucleus, and fibres of both large and small size continuing onward. ( $\times 550$.

Fig. 15.-Normal fibres in the pons. Note the smooth outline and uniform staining. Such fibres are also stained green-blue, rather than purple as are degenerating fibres. ( $\times 550$.)

FIG. 16.--Apparently normal fibres in the internal capsule which show slight varicose thickenings but do not show the metachromasia of degeneration. ( $\times$ 550.)

Fig. 17.-Detail showing optic tract fibres of different size, both of which have nodal constrictions. The swelling in the smaller fibre appears most marked on either side of the constriction. $(\times 1,100$.

FIG. 18.-Deeply stained node on a degenerating fibre in the brachium of the superior colliculus four days after enucleation of the contralateral eye. $(\times 1,250$. $)$

FIG. 19.-Fibre bifurcation in the optic tract, showing deeply stained nodal cuff at the site of branching. $(\times 1,100$.)

FIG. 20.-Degenerating fibre in the pretectum, showingo the typical dark cuff at the site of bifurcation. $(\times 1,100$.)

FIG. 21.-Detail of degeneration in fine fibre. $(\times 1,100$.

FIG. 22.-Detail in large degenerating fibre. $(\times 1,100$.

Plate V.

FIG. 23.-Pretectum, showing disintegration of fime fibres and preterminals amongst the cells of the pretectal nucleus. ( $\times$ 550.) (Compare with Fig. 8.)

FIG. 24.-Normal terminal ring on a nerve cell of the large-cell nucleus of the optic tract. $(\times 1,250$.

FIG. 25.-Enlarged and deeply stained terminal plaques on a nerve cell of the large-cell nucleus of the optic tract four days after enucleation of the opposite eye. $(\times 1,250$.

Fig. 26.-Enlarged terminal boutons on a ganglion cell in the dorsal nucleus of the lateral geniculate body on the side opposite to the lesion. $(\times 1,250$.)

FIG. 27.-Pontine cell, showing coarse perinuclear material as well as fine granulation throughout the cytoplasm. $(\times 1,000$.

Fig. 28.-Nerve cells of the frontal cortex, showing fine cytoplasmic granulation. $(\times 1,000$.)

FIG. 29.-Cells and fibres of the pons, showing staining of neuropil. ( $\times$ 65.)

FIG. 30.-Ependymal cells of the lining of the third ventricle. $(\times 625$. 


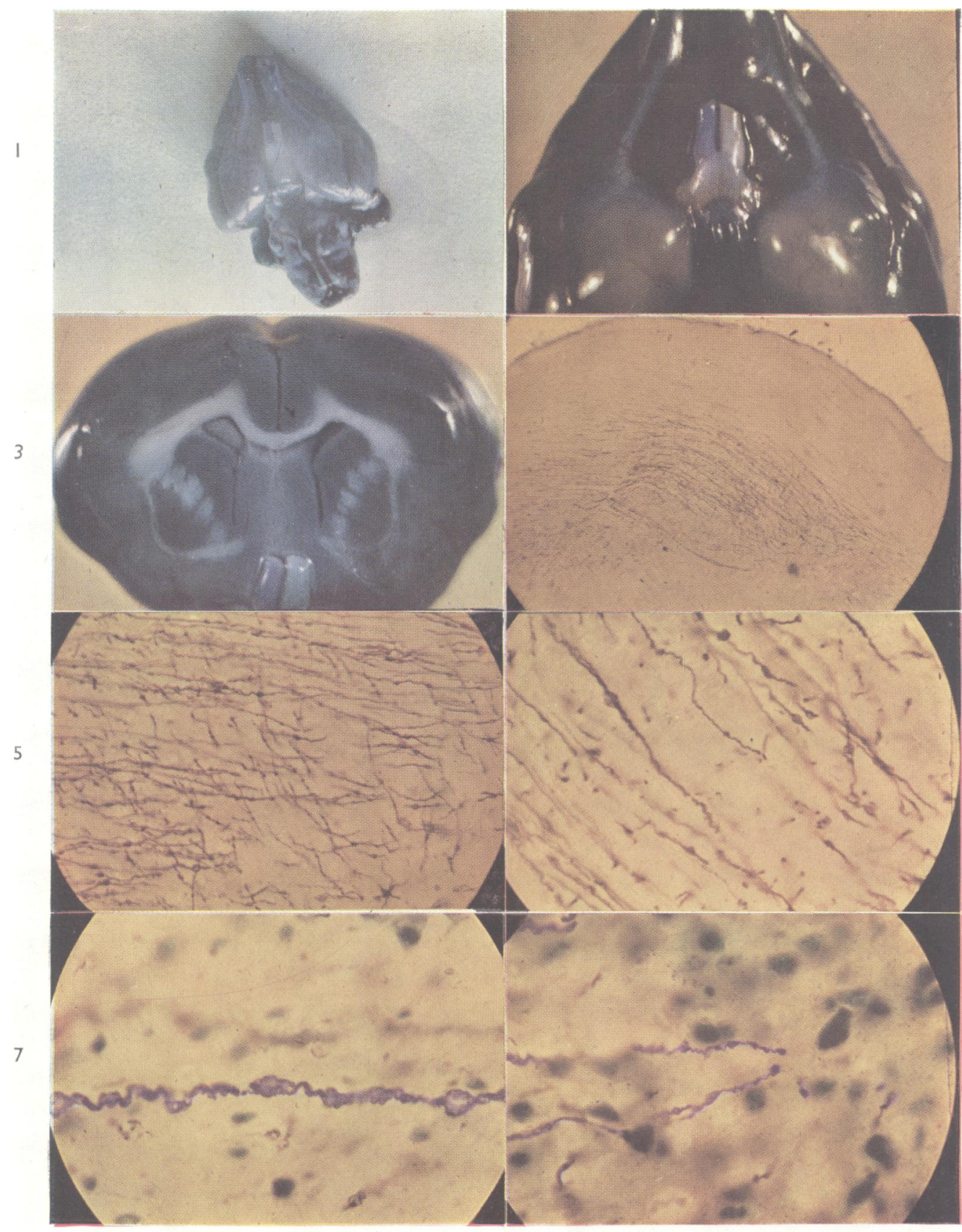

Plate I. 


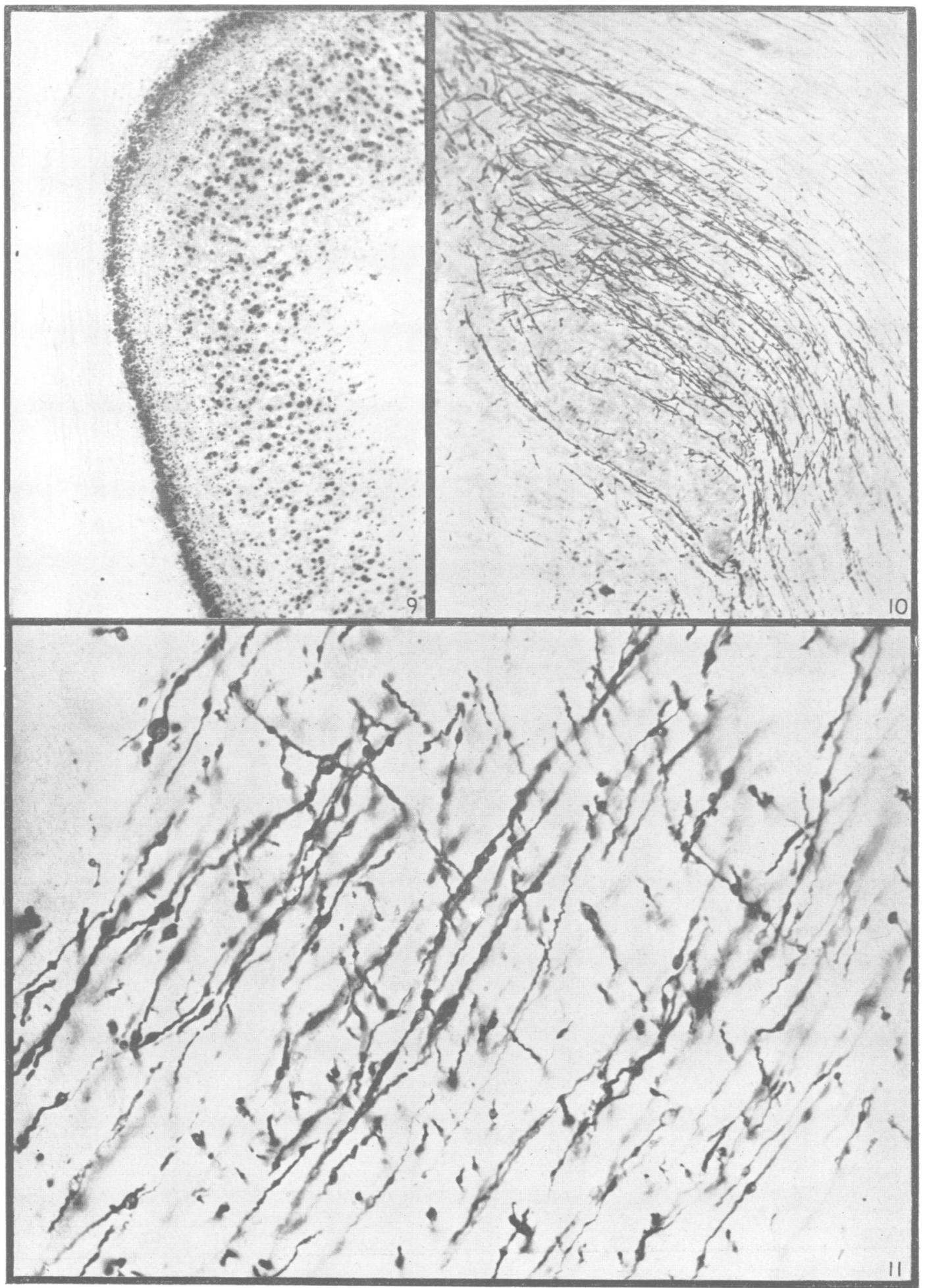




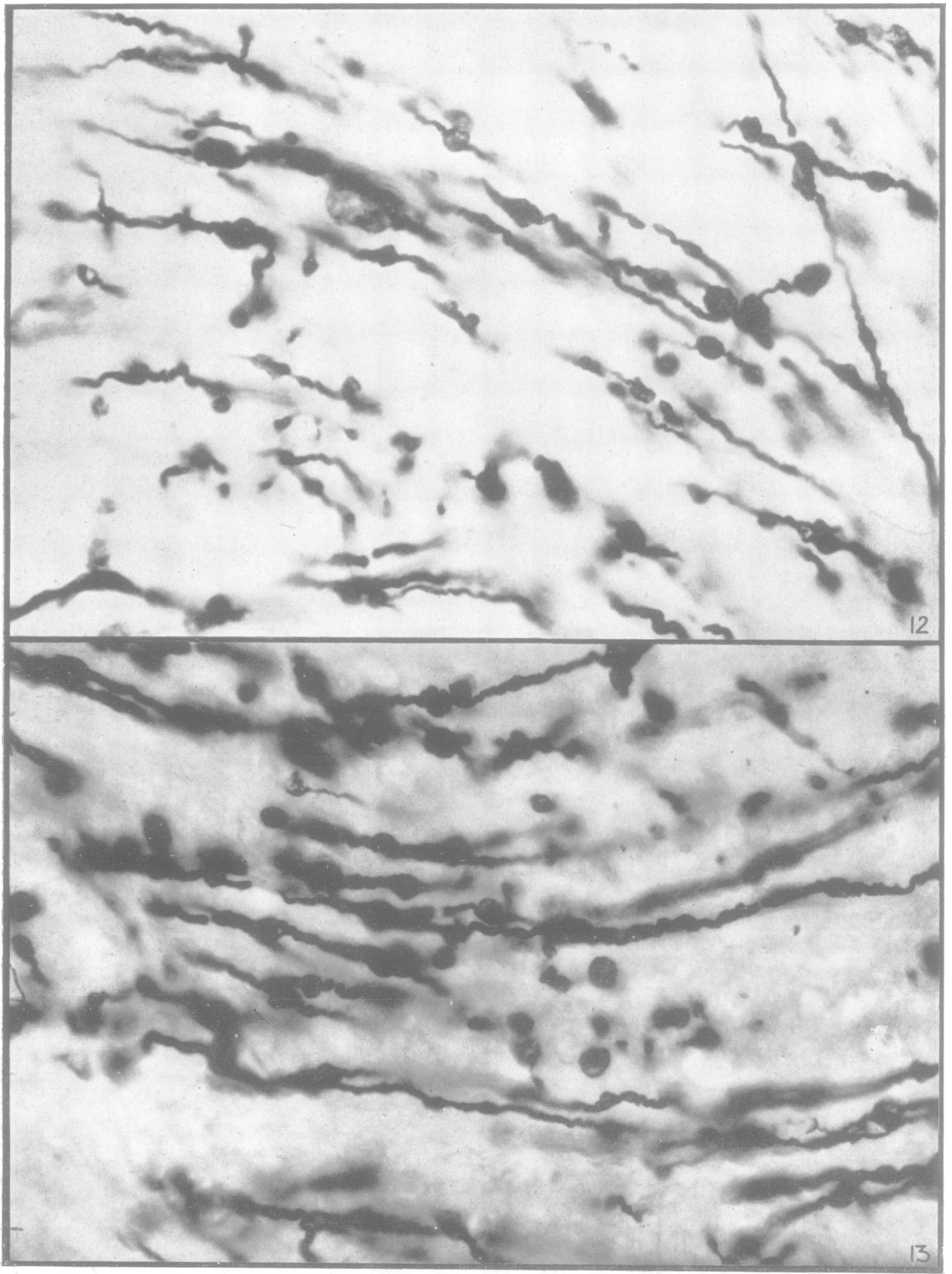

Plate III. 


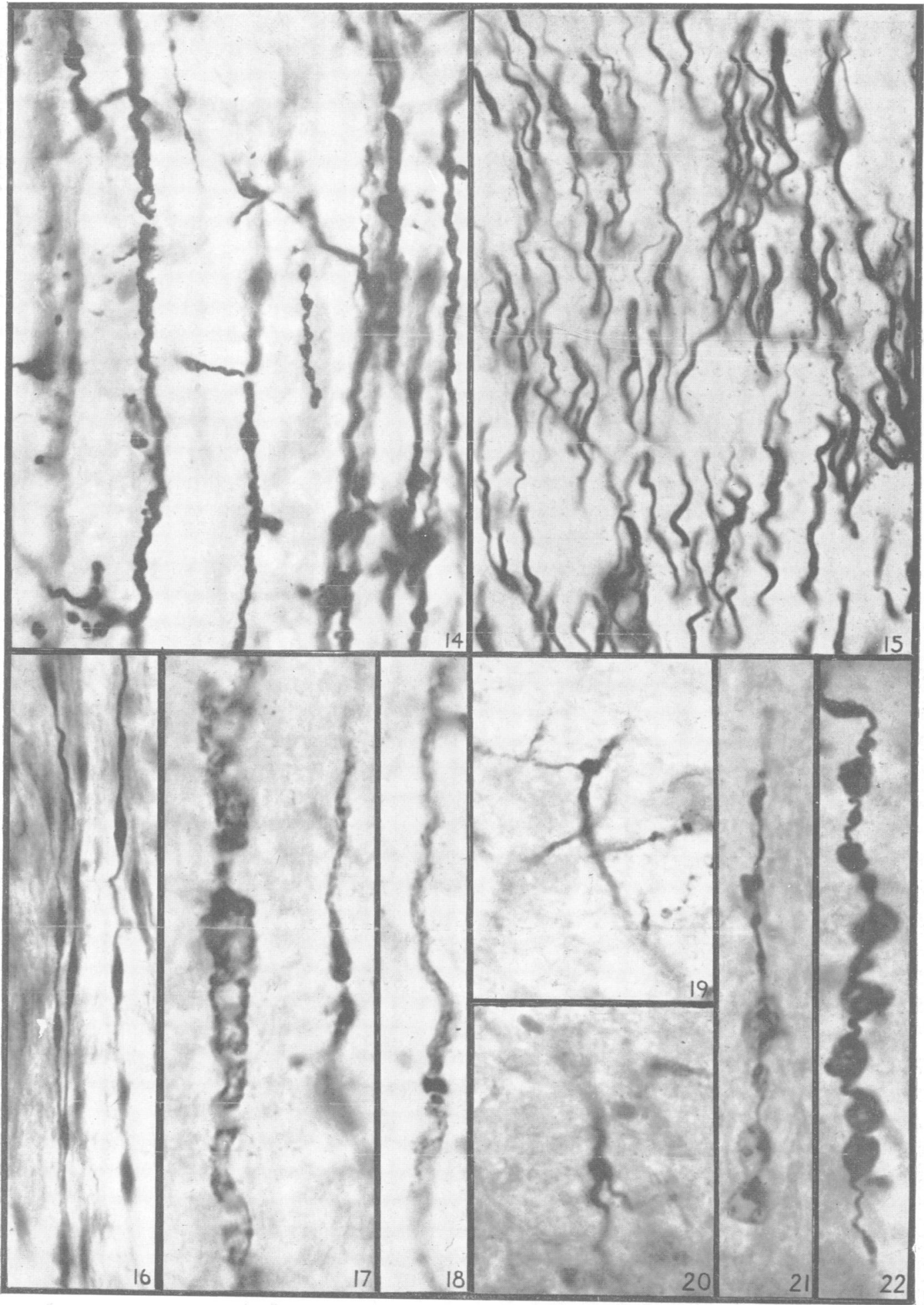

Plate IV.

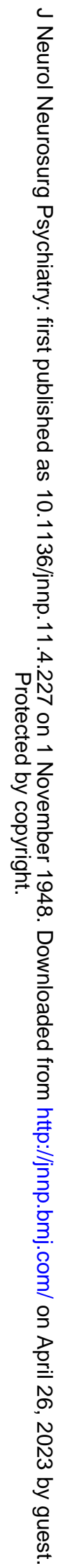




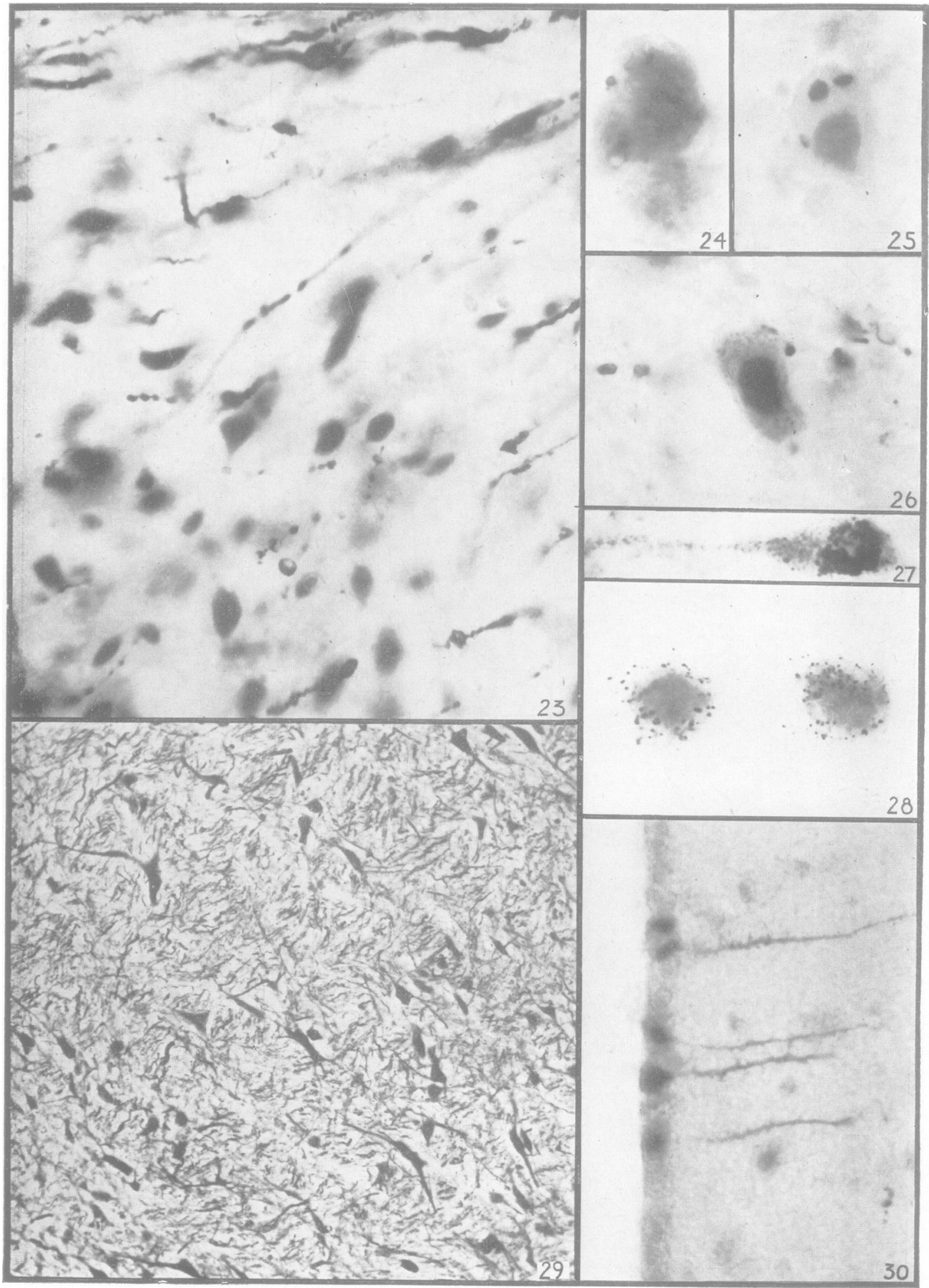

Plate V. 